Solid State Ionics 6 (1982) 159-170

North-Holland Publishing Company

\title{
EFFECT OF GRAIN BOUNDARIES ON THE CONDUCTIVITY OF HIGH-PURITY $\mathrm{ZrO}_{2}-\mathrm{Y}_{2} \mathrm{O}_{3}$ CERAMICS
}

\author{
M.J. VERKERK, B.J. MIDDELHUIS and A.J. BURGGRAAF \\ Twente University of Technology, Department of Inorganic Materials Science, \\ 7500 AE Enschede, The Netherlands
}

Received 20 November 1981

\begin{abstract}
Grain boundary conductivities are determined by complex impedance measurements $\left(1-10^{6} \mathrm{~Hz}\right)$ on high-purity ceramics prepared by the alkoxide synthesis and on less pure ceramics obtained from a commercial powder. The grain size was varied systematically in the region $0.36-55 \mu \mathrm{m}$. The grain boundary conductivity is strongly influenced by the grain size, impurities and cooling procedure. The grain boundary conductivity increases linearly with the grain size for small grain sizes $(0.3$ to $2-4 \mu \mathrm{m})$ and is constant for larger grain sizes. The calculated specific conductivity of the grain boundary for pure materials is about 100 times smaller than that of the bulk. The grain boundary thickness was estimated to be $5.4 \mathrm{~nm}$. The activation energy of the grain boundary conductivity is $7 \mathrm{~kJ}^{\mathrm{mole}}{ }^{-1}$ higher than that of the bulk.
\end{abstract}

\section{Introduction}

In recent years considerable attention has been paid to oxygen ion conductors from a fundamental as well as an applied point of view. Oxygen ion conductors have been used in galvanic cells for measuring thermodynamic and kinetic reactions, in oxygen sensors for automotive control and the regulation of other combustion processes, for the measurement of activities in molten metals, in oxygen pumps to produce enriched air, in fuel cells for the production of electricity and in electrocatalytic devices.

The conductivity of ceramic cubic stabilized zirconia as a solid electrolyte depends on the physical and chemical properties of the samples such as composition, ordering and ageing effects, porosity, grain size and purity. At high temperatures the influence of grain boundaries and impurities on the conductivity is small. However, at intermediate and low temperatures the influence of grain boundaries and impurities on the conductivity can be considerable. Knowledge of the properties of grain boundaries is important because the solid electrolyte in the above-mentioned devices is frequently used in the form of polycrystalline fine-grained thin films, while the need for lower working temperatures is important in practice.
The conductivity of grain boundaries is strongly influenced by the purity of the samle, as shown by various authors [1-7]. The reported results show a considerable scatter and are rather conflicting. Sometimes, the impurities are introduced purposely in order to lower the sintering temperature required, or to improve the density or strength. The influence of impurities on the conductivity has been attributed to the segregation of impurities and the formation of second phases. The existence of second phases, consisting mainly of $\mathrm{Si}, \mathrm{Al}, \mathrm{Mg}$ and $\mathrm{Ca}$ impurities, was shown by Beekmans and Heyne [3].

The conductivity of the bulk and the grain boundaries is strongly influenced by the porosity, as shown by Bernard [5]. When the porosity is less than $25 \%$, the conductivity decreases linearly with increasing porosity.

The influence of the grain size was studied by Inozemtsev et al. [8], Ioffe et al. [9], Chu and Seitz [10] and Bernard [5]. According to Inozemtsev et al. [8] the grain boundary conductivity of $\mathrm{ZrO}_{2}-\mathrm{Sc}_{2} \mathrm{O}_{3}$ (10 mole \%) ceramics increases with increasing grain size. Analysis of the grain boundary conductivity data of Ioffe et al. [9] for $\mathrm{ZrO}_{2} \mathrm{Y}_{2} \mathrm{O}_{3}(5.7 \mathrm{~mole} \%)$ ceramics showed a linear increase of the grain boundary conductivity $\sigma_{\mathrm{gb}}$ with the grain size $d_{\mathrm{g}}$ in the re- 
gion of $d_{\mathrm{g}}=4.5-18 \mu \mathrm{m}$. The grain boundary conductivity of the sample with a grain size of $0.2 \mu \mathrm{m}$ is larger than expected on the basis of this linear relation. From Bernard's data [5] we found that in the region of $d_{\mathrm{g}}=0.8-10 \mu \mathrm{m}, \sigma_{\mathrm{gb}}$ increases linearly with increasing grain size, whereas for the sample with $d_{\mathrm{g}}=16 \mu \mathrm{m}$ $\sigma_{\mathrm{gb}}$ is higher than expected on the basis of this relation. From the study of Chu and Seitz [10] no conclusions can be drawn for the relation between $\sigma_{\mathrm{gb}}$ and $d_{\mathrm{g}}$ because the conductivity is largely influenced by the high porosity of the samples. The electrical behaviour of fine grain-sized ceramics has not yet been studied thoroughly.

Inozemtsev et al. [8] and Bernard [5] showed that the grain boundary conductivity is strongly influenced by the thermal history. Bernard [5] showed that after quenching from high temperatures no contribution of the grain boundaries could be measured whereas after annealing at a lower temperature the influence of the grain boundaries was considerable.

Analysis of literature data for calcia and lanthanide substituted zirconias ( $\mathrm{fcc}$ ) shows that the activation energy of the grain boundary is $5-20 \mathrm{~kJ} \mathrm{~mole}^{-1}$ higher than that of the bulk [5,6,9-12]. Inozemtsev and Perfil'ev [12] showed that the activation energies of the grain boundary and bulk conductivity in the $\left(\mathrm{ZrO}_{2}\right)_{1-x}\left(\mathrm{YO}_{1.5}\right)_{x}$ system have the same dependency on the yttrium oxide concentration. In the $\left(\mathrm{CeO}_{2}\right)_{1-x}\left(\mathrm{YO}_{1.5}\right)_{x}$ [13] and $\left(\mathrm{ThO}_{2}\right)_{1-x}\left(\mathrm{YO}_{1.5}\right)_{x}$ [11] systems with $x=0.00-0.02$ and in the $\mathrm{ZrO}_{2}-$ $\mathrm{Gd}_{2} \mathrm{O}_{3}$ (pyrochlore) [6] system the activation energy of the grain boundary is considerably higher than that of the bulk.

The object of this paper is to study the electrical properties of grain boundaries of high-purity ceramic samples with a well-defined microstructure and grains with a size of $0.3-20 \mu \mathrm{m}$. The conductivity data of these samples are compared with those of samples made from a commercial powder. The influence of low concentrations of $\mathrm{Al}, \mathrm{Bi}$ and $\mathrm{Fe}$ impurities on the grain boundary and bulk conductivity is under investigation and will be published subsequently [14].

\section{Experimental}

\subsection{Specimen preparation and characterization}

Ceramic samples of $\left(\mathrm{ZrO}_{2}\right)_{1-x}\left(\mathrm{YO}_{1.5}\right)_{x}$ were prepared from powders obtained by hydrolysis of zirconium and yttrium alkoxides $[15,16]$. $\mathrm{Zr}\left(\mathrm{OC}_{5} \mathrm{H}_{11}^{\mathrm{t}}\right)_{4}$ was synthetized from $\mathrm{ZrCl}_{4}$ (MerckSchuchhardt) and $\mathrm{Y}\left(\mathrm{OC}_{3} \mathrm{H}_{7}^{\mathrm{i}}\right)_{3}$ from metallic Y-chips (Alfa-Ventron, M3N). A diluted metal alkoxidebenzene solution was added dropwise to a large excess of water while vigorously stirring. The hydroxide was twice washed with water and three times with isopropanol, dried at $125^{\circ} \mathrm{C}$ and calcined at $650^{\circ} \mathrm{C}$ for $2 \mathrm{~h}$. After calcination the powder was dry-milled in a teflon ball-mill.

A commercial powder with the composition $\left(\mathrm{ZrO}_{2}\right)_{1-x}\left(\mathrm{YO}_{1.5}\right)_{x}(x=0.14)$ was obtained from Zircar (Zircar products Inc., Florida, New York, USA).

The powders were isostatically pressed at $400 \mathrm{MPa}$ and sintered in air in a tube furnace. The temperaturetime curve is given for two temperatures in fig. 1 . For sintering at $1973 \mathrm{~K}$ a furnace was used with another temperature-time cycle: heating-up in $10 \mathrm{~h}$ to $1973 \mathrm{~K}$, sintering for $3 \mathrm{~h}$ at this temperature, coolingdown to 1673 within 3 min and then cooling-down to room temperature during $10 \mathrm{~h}$ (oxygen atmosphere).

The composition was measured using X-ray fluorescence, the accuracy is $0.1 \%$. Al, Si impurities were measured according to [17]. C was analysed after quantitative combustion by the method described in [18]. The concentration of other impurities was measured using $\mathrm{X}$-ray fluorescence and emission spectrometry.

The grain size distribution of the alkoxide samples was estimated from 1000 to 2000 grains using the

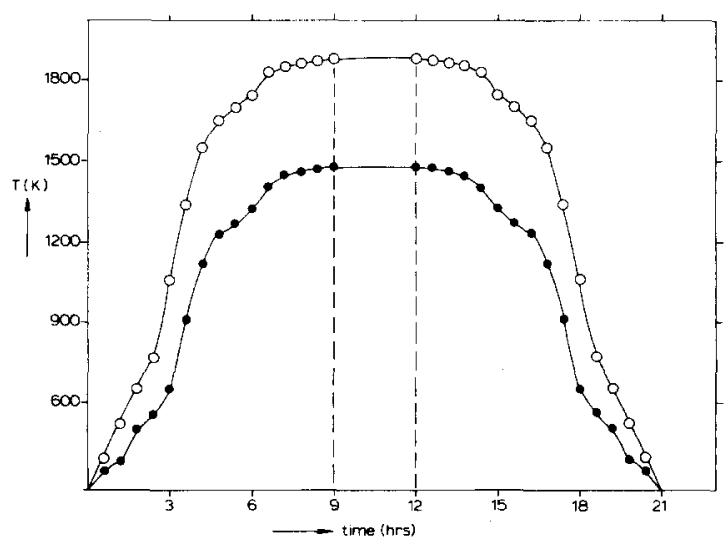

Fig. 1. Temperature-time curve of the thermal treatment of the samples for two temperatures. Between the dashed lines the temperature was kept constant. $\bullet: 1473 \mathrm{~K}, \circ: 1873 \mathrm{~K}$. 
correction method described by Oel [19]. The grain size of the Zircar specimen was measured with the Mendelssohn line intersection method [20].

The crystal structures of the specimens were identified by a Philips PW 1370 diffractometer. The ceramic structures of polished and thermally etched samples were investigated with a scanning electron microscope (SEM) type JEOL JSMU3. The density of the samples was measured at $298 \mathrm{~K}$ by the Archimedes method using mercury.

\subsection{Electrical measurements}

$\mathrm{AC}$ conductivity measurements in the frequency range $10^{1}-10^{6} \mathrm{~Hz}$ were performed in air on samples with a diameter of 5-10 $\mathrm{mm}$ and a thickness of $0.5-$ $2 \mathrm{~mm}$ in the temperature region of $600-1000 \mathrm{~K}$. Platinum electrodes were sputtered on both sides. A Solartron 1174 Frequency Response Analyser was used; the electrical circuit is given in fig. 2 . The measurements were performed in the $y / x$-mode with a sample voltage of $10 \mathrm{mV}$. The impedance of the sample $Z=Z^{\prime}-\mathrm{i} Z^{\prime \prime}$ was calculated from the measured impedance $Z_{\mathrm{m}}=a-\mathrm{i} b$ according to: $Z^{\prime}=(a-1) R_{\mathrm{ref}}$, $Z^{\prime \prime}=b R_{\text {ref. }} R_{\text {ref }}$ was $2-10$ times smaller than the impedance of the sample. The data were corrected for the induction and the resistivity of the cell and the electrical wires.

The equipment was tested using dummy cells. It appeared that due to capacitative effects of the response analyser no measurements could be performed at high frequencies when the impedance of the samples is high, e.g. when the impedance of the sam-

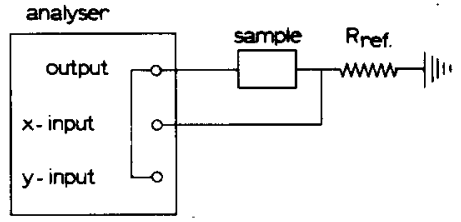

Fig. 2. Electrical circuit of the analyser and the sample.

ples is $10^{4} \Omega$, the maximum frequency which can be meaningfully used is $10^{5} \mathrm{~Hz}$.

\section{Results}

\subsection{Characterization of the specimens}

X-ray diffraction showed that all the samples had a face centered cubic structure.

The composition and a survey of the most important impurities in the powders and sintered specimens is given in table 1 . The $\mathrm{Hf}, \mathrm{Fe}, \mathrm{Ca}$ and $\mathrm{Ti}$ impurities are measured with $\mathrm{X}$-ray fluorescence. The concentration of $\mathrm{Cd}, \mathrm{Ba}, \mathrm{Sr}, \mathrm{Ce}, \mathrm{Nb}, \mathrm{Pr}, \mathrm{Ta}, \mathrm{Te}$ and $\mathrm{Th}$ impurities in the powders and sintered samples, as shown by X-ray fluorescence, is $<0.1 \mathrm{wt} \%$ (detection limit). The concentration of other impurities was checked with emission spectrometry and appeared to be lower than the detection limit (generally $0.01-0.001 \mathrm{wt} \%$ ). From table 1 we conclude that there are no measurable changes in the bulk concentrations of the im. purities during sintering. The commercial Zircar powder has a higher concentration of $\mathrm{Fe}, \mathrm{Ca}$ and $\mathrm{Ti}$ impurities.

Table 1

Composition and impurities of the starting powders and sintered samples

\begin{tabular}{|c|c|c|c|c|c|c|c|c|c|}
\hline Powder & $\begin{array}{l}\text { Sintering temp. } \\
\text { (K) }\end{array}$ & $\begin{array}{l}\mathrm{YO}_{1.5} \\
(\mathrm{at} \%)\end{array}$ & $\begin{array}{l}\text { Hf } \\
(\mathrm{wt} \%)\end{array}$ & $\begin{array}{l}\text { Si } \\
\left(10^{-2} \cdot w t \%\right)\end{array}$ & $\begin{array}{l}\mathrm{Al} \\
\left(10^{-2} \mathrm{wt} \%\right)\end{array}$ & $\begin{array}{l}\mathrm{Fe} \\
\left(10^{-2} \mathrm{wt} \%\right)\end{array}$ & $\begin{array}{l}\mathrm{Ca} \\
\left(10^{-2} w t \%\right)\end{array}$ & $\begin{array}{l}\mathrm{Ti} \\
\left(10^{-2} \mathrm{wt} \%\right)\end{array}$ & $\begin{array}{l}\mathrm{C} \\
\left(10^{-2} w t \%\right)\end{array}$ \\
\hline Alkoxide & - & 11.9 & 2.0 & 19 & 2 & 2 & & & 67 \\
\hline \multirow{3}{*}{ Alkoxide } & - & 16.4 & 2.0 & 4 & 3 & 0.3 & 4a) & 1 a) & 30 \\
\hline & 1473 & 16.4 & 2.0 & 4 & 3 & 0.5 & 4 a) & 1 a) & 10 \\
\hline & 1873 & 16.4 & 2.0 & 4 & 2 & 0.5 & $4^{\text {a) }}$ & 1 a) & 10 \\
\hline \multirow[t]{3}{*}{ Zircar } & - & 14.0 & 1.5 & 5 & 4 & 1 & 30 & 10 & \\
\hline & 1523 & 14.0 & 1.5 & 5 & 4 & 1 & 30 & 10 & \\
\hline & 1973 & 14.0 & 1.5 & 5 & 4 & 1 & 30 & 10 & \\
\hline
\end{tabular}

a) Detection limit. 

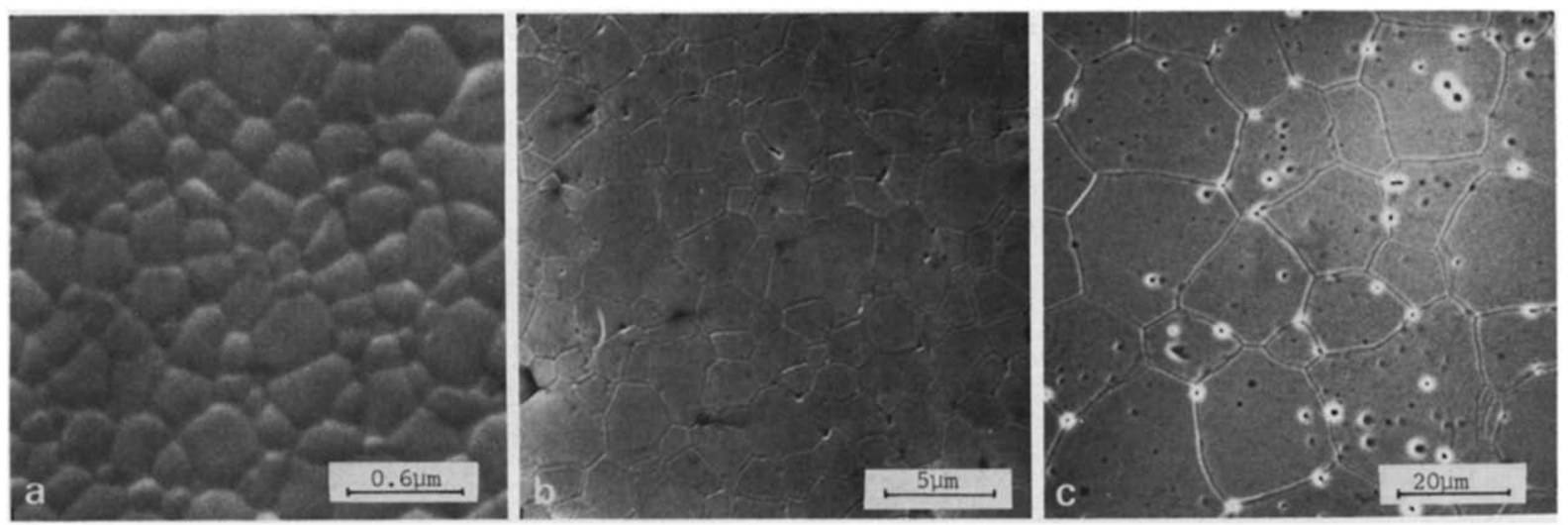

Fig. 3. SEM photographs of $\left(\mathrm{ZIO}_{2}\right)_{1-x}\left(\mathrm{YO}_{1.5}\right)_{x}, x=0.164$, sintered at $1456 \mathrm{~K}$ (a), $1673 \mathrm{~K}$ (b) and $1973 \mathrm{~K}$ (c) (alkoxide samples).

The microstructure of the alkoxide materials is shown in fig. 3 for samples sintered at several temperatures. There are a few isolated pores on the grain boundaries and some are located within the grains. Some of the grain boundaries are curved, indicating that the grain growth has not completely stopped and the grain boundary exist in a non-equilibrium state.

The sintering temperature, density, average grain size and standard deviation of the grain size distribution of all samples is given in table 2. Fig. 4 gives a representative grain size distribution of the samples sintered at $1676 \mathrm{~K}$.

Table 2

Sintering temperature, grain size, density and electrical data for $\left(\mathrm{ZrO}_{2}\right)_{1-x}\left(\mathrm{YO}_{1 \cdot 5}\right)_{x}$

\begin{tabular}{|c|c|c|c|c|c|c|c|}
\hline $\begin{array}{l}\text { Sintering temp. } \\
\text { (K) }\end{array}$ & $d_{\mathrm{g}}(\mu \mathrm{m})$ & $\begin{array}{l}\text { Density } \\
(\%)\end{array}$ & $\begin{array}{l}E_{\mathrm{a}}(\mathrm{b}) \\
\left(\mathrm{kJ} \mathrm{mole}^{-1}\right)\end{array}$ & $\begin{array}{l}\log \sigma_{0}(\mathrm{~b}) \\
\left(\Omega^{-1} \mathrm{~m}^{-1}\right)\end{array}$ & $\begin{array}{l}E_{\mathrm{a}}(\mathrm{gb}) \\
\left(\mathrm{kJ} \mathrm{mole}^{-1}\right)\end{array}$ & $\begin{array}{l}\log \sigma_{0}(\mathrm{gb}) \\
\left(\Omega^{-1} \mathrm{~m}^{-1}\right)\end{array}$ & $\begin{array}{l}\sigma_{\mathrm{b}}(723 \mathrm{~K}) \\
\left(10^{-2} \Omega^{-1} \mathrm{~m}^{-}\right.\end{array}$ \\
\hline \multicolumn{8}{|c|}{ alkoxide material, $x=0.119$} \\
\hline \multicolumn{8}{|c|}{ alkoxide material, $x=0.164$} \\
\hline $\begin{array}{l}1456 \\
1473 \\
1523 \\
1545 \\
1587 \\
1676 \\
1786 \\
1823 \\
1873 \\
1973 \text { a) }\end{array}$ & $\begin{array}{l}0.36(0.10) \\
0.55(0.21) \\
0.75(0.26) \\
1.11(0.29) \\
1.35(0.49) \\
2.54(0.84) \\
5.0(1.7) \\
8.2(2.5) \\
13.5(4.8) \\
21.4(7.0)\end{array}$ & $\begin{array}{l}95.7 \\
95.6 \\
98.1 \\
96.0 \\
99.1 \\
99.5 \\
99.4 \\
99.0 \\
99.0 \\
99.0\end{array}$ & $\begin{aligned} 103 & \pm 2 \\
101 & \pm 3 \\
103 & \pm 2 \\
104 & \pm 2 \\
103 & \pm 1 \\
99 & \pm 2 \\
105 & \pm 1 \\
108 & \pm 5 \\
103 & \pm 2 \\
104 & \pm 2\end{aligned}$ & $\begin{array}{l}5.83 \pm 0.16 \\
5.85 \pm 0.21 \\
6.00 \pm 0.16 \\
6.08 \pm 0.18 \\
5.99 \pm 0.05 \\
5.76 \pm 0.13 \\
6.15 \pm 0.08 \\
6.34 \pm 0.35 \\
5.98 \pm 0.1 .2 \\
5.06 \pm 0.17\end{array}$ & $\begin{array}{l}112 \pm 4 \\
114 \pm 3 \\
109 \pm 3 \\
108 \pm 2 \\
109 \pm 4 \\
108 \pm 5 \\
108 \pm 3 \\
110 \pm 10 \\
110 \pm 4 \\
107 \pm 5\end{array}$ & $\begin{array}{l}6.61 \pm 0.30 \\
7.02 \pm 0.21 \\
6.65 \pm 0.24 \\
6.61 \pm 0.15 \\
6.80 \pm 0.27 \\
7.08 \pm 0.37 \\
7.24 \pm 0.23 \\
7.37 \pm 0.70 \\
7.39 \pm 0.26 \\
7.33 \pm 0.37\end{array}$ & $\begin{array}{l}2.55 \\
3.46 \\
3.45 \\
3.60 \\
3.44 \\
4.28 \\
3.47 \\
3.51 \\
3.38 \\
3.39\end{array}$ \\
\hline \multicolumn{8}{|c|}{ Zircar material, $x=0.140$} \\
\hline $\begin{array}{l}1473 \\
1574 \\
1673 \\
1773 \\
1973 \text { a) }\end{array}$ & $\begin{array}{l}0.65 \\
0.86 \\
4.2 \\
11 \\
55\end{array}$ & $\begin{array}{l}88.2 \\
89.3 \\
93.7 \\
96.1 \\
92.5\end{array}$ & $\begin{array}{l}96 \pm 1 \\
93 \pm 2 \\
97 \pm 1 \\
91 \pm 3 \\
94 \pm 1\end{array}$ & $\begin{array}{l}5.47 \pm 0.10 \\
5.27 \pm 0.10 \\
5.62 \pm 0.07 \\
5.17 \pm 0.25 \\
5.35 \pm 0.06\end{array}$ & $\begin{array}{r}107 \pm 2 \\
101 \pm 2 \\
104 \pm 2 \\
99 \pm 3 \\
96 \pm 3\end{array}$ & $\begin{array}{l}5.76 \pm 0.13 \\
5.70 \pm 0.14 \\
6.27 \pm 0.08 \\
5.96 \pm 0.19 \\
5.98 \pm 0.22\end{array}$ & $\begin{array}{l}3.15 \\
4.02 \\
3.93 \\
4.12 \\
3.30\end{array}$ \\
\hline
\end{tabular}

a) These samples were subjected to a different temperature treatment (see text). 


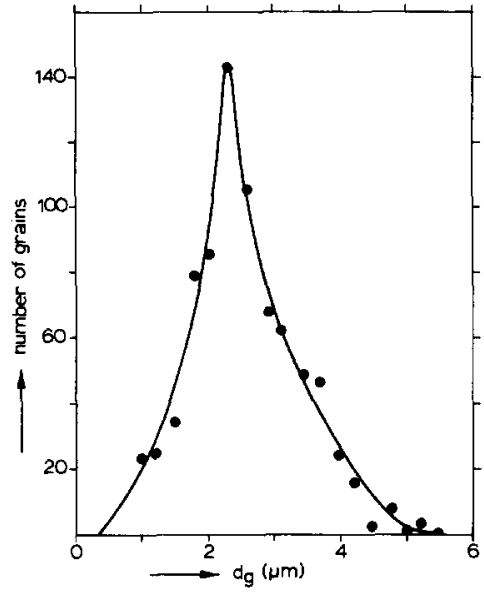

Fig. 4. Grain size distribution of $\left(\mathrm{ZrO}_{2}\right)_{1-x}\left(\mathrm{YO}_{1.5}\right)_{x}, x=$ 0.164 , sintered at $1673 \mathrm{~K}$ and corrected after [19], $d_{\mathrm{g}}=$ $2.54 \pm 0.84 \mu \mathrm{m}$.

\subsection{Complex impedance measurements}

The frequency dispersion measurements were analysed using the brick layer model proposed by Van Dijk and Burggraaf [6]. This model is developed for pure samples with a well-developed microstructure and will be discussed in section 4.1. In this model the following relations are valid between the measured conductivity and capacity data and the microstructural data of the grain boundary:

$\sigma_{\mathrm{gb}}=\sigma_{\mathrm{gb}}^{\mathrm{sp}} d_{\mathrm{g}} / \delta_{\mathrm{gb}}$,

$C_{\mathrm{gb}}=\epsilon_{0} \epsilon_{r}(\mathrm{gb})\left(d_{\mathrm{g}} / \delta_{\mathrm{gb}}\right)$,

with $\delta_{\mathrm{gb}}$ is the thickness of the grain boundary, $\sigma_{\mathrm{gb}}^{\mathrm{sp}}$ the grain boundary conductivity corrected for the dimensions of the grain boundary, $\epsilon_{0}$ the permittivity of free space and $\epsilon_{r}(\mathrm{gb})$ the permittivity of the grain boundary material. The equivalent electrical circuit associated with this model, together with the complete impedance diagram, is given in fig. 5 . The relevant conductivity and capacity data were determined using the following equations:

$R_{\mathrm{b}}=R_{1}(A / L)$,

$R_{\mathrm{gb}}=\left(R_{2}-R_{1}\right)(A / L)$,

$R_{\mathrm{el}}=\left(R_{3}-R_{2}\right)(A / L)$, (a)

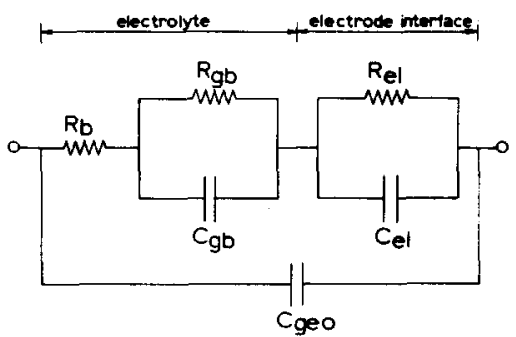

(b)

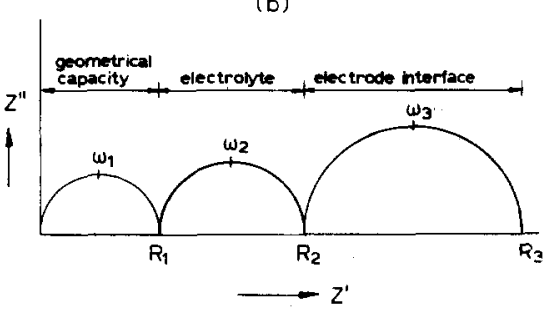

Fig. 5.(a) Equivalent electrical circuit associated with the brick layer model; (b) complex impedance diagram of this circuit. $R$ is resistance and $C$ capacity. The suffixes $\mathrm{b}, \mathrm{gb}$, el and geo denote bulk, grain boundary, electrode and geometrical, respectively.

$C_{\text {geo }}=\left(1 / R_{1} \omega_{1}\right)(L / A)$,

$C_{\mathrm{gb}}=\left[1 /\left(R_{2}-R_{1}\right) \omega_{2}\right](L / A)$,

$C_{\mathrm{el}}=\left[1 /\left(R_{3}-R_{2}\right) \omega_{3}\right](L / A)$,

with $A / L$ is the area/length ratio of the sample and the frequency $\omega=2 \pi f$.

The different parts of the frequency dispersion diagrams were identified by variations of the length/ area ratio and the oxygen partial pressure. Fig. 6

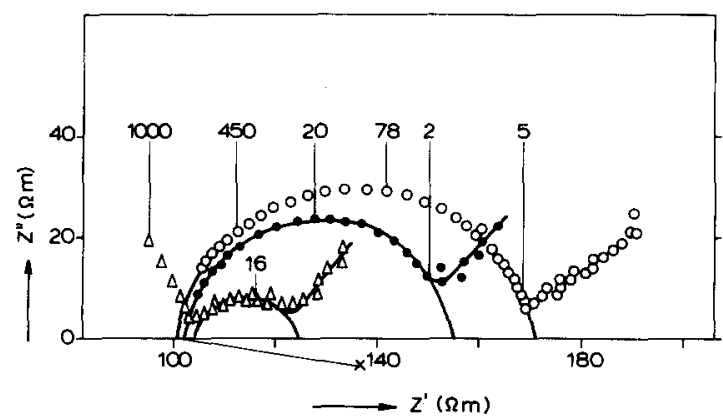

Fig. 6. Complex impedance diagrams for alkoxide samples $(x=0.164)$ at $673 \mathrm{~K} . \circ: d_{\mathrm{g}}=0.55 \mu \mathrm{m}, \bullet: d_{\mathrm{g}}=1.35 \mu \mathrm{m}$ and $\Delta: d_{\mathrm{g}}=5.04 \mu \mathrm{m}$. The frequency is given in $\mathrm{kHz}$. 
shows the semicircle associated with the grain boundary dispersion for samples with different grain sizes. The diameter of the semicircle increases with decreasing grain size and is absent for single crystalline samples $[1,5,6,11]$. Parts of circles due to electrode effects and the geometrical capacity are present. The depression of the grain boundary dispersion semicircle does not vary with temperature or grain size and has a value of $7-9^{\circ}$ indicating a relatively small scatter of relaxation times.

Figs. 7 and 8 give the electrical data of the bulk and the grain boundary as a function of temperature. Usually the electrical data of the bulk are depicted as conductivities $\left(\sigma_{\mathrm{b}}=1 / R_{\mathrm{b}}\right)$ and therefore, the electrical data of the grain boundary are depicted in the same way $\left(\sigma_{\mathrm{gb}}=1 / R_{\mathrm{gb}}\right)$. For reasons of clarity the bulk conductivity for only one sample is given and several grain boundary plots have been omitted. At about $800 \mathrm{~K}$ a bend in the Arrhenius plot of $\sigma_{b}$ is observed. At $T \sim 800 \mathrm{~K}$ the activation energy for the alkoxide sample changes from $(104 \pm 2)$ to $(79 \pm 4)$

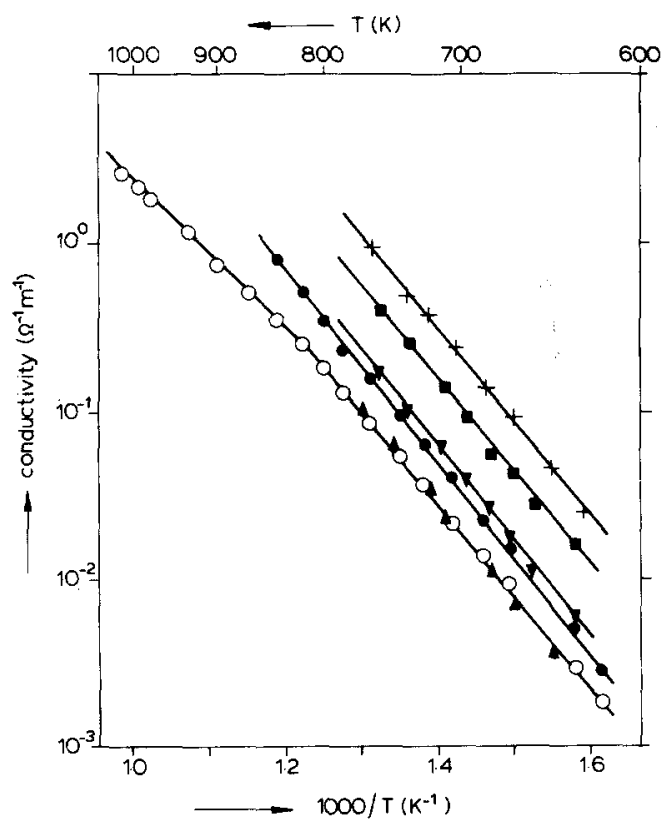

Fig. 7. Bulk and grain boundary conductivity for alkoxide samples, $x=0.164$, as a function of temperature. $0: \sigma_{\mathrm{b}}, d_{\mathrm{g}}=$ $1.11 \mu \mathrm{m}, \Delta ; \sigma_{\mathrm{gb}}, d_{\mathrm{g}}=0.36 \mu \mathrm{m}, \bullet: \sigma_{\mathrm{gb}}, d_{\mathrm{g}}=1.11 \mu \mathrm{m}$, $\nabla: \sigma_{\mathrm{gb}}, d_{\mathrm{g}}=1.35 \mu \mathrm{m}, \omega: \sigma_{\mathrm{gb}}, d_{\mathrm{g}}=2.54 \mu \mathrm{m},+: \sigma_{\mathrm{gb}}, d_{\mathrm{g}}=$ $21.4 \mu \mathrm{m}$.

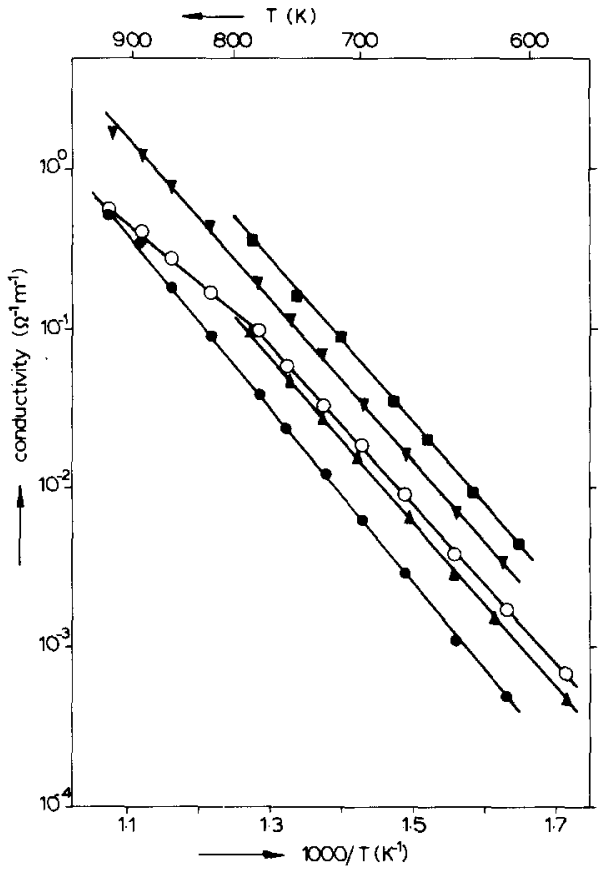

Fig. 8. Bulk and grain boundary conductivity for Zircar samples as a function of temparature: $0: \sigma_{\mathrm{b}}, d_{\mathrm{g}}=0.65 \mu \mathrm{m}, \bullet$ : $\sigma_{\mathrm{gb}}, d_{\mathrm{g}}=0.65 \mu \mathrm{m}, \wedge: \sigma_{\mathrm{gb}}, d_{\mathrm{g}}=0.86 \mu \mathrm{m}, \nabla: \sigma_{\mathrm{gb}}, d_{\mathrm{g}}=11 \mu \mathrm{m}$, m: $\sigma_{\mathrm{gb}}, d_{\mathrm{g}}=55 \mu \mathrm{m}$.

$\mathrm{kJ}$ mole -1 and for the Zircar sample from $(96 \pm 1)$ to $(72 \pm 2) \mathrm{kJ}$ mole ${ }^{-1}$. This bend was observed at about the same temperature by other investigations $[1,5,11,21]$ and is correlated with vacancy trapping by the dopant [21]. However, no bend in the Arrhenius plot of the grain boundary is observed in the investigated temperature regions, as shown clearly in fig. 8 .

Table 2 summarizes the activation energy $E_{\mathrm{a}}$ and $\log \sigma_{0}$ of the bulk and grain boundary conductivity of all samples. The deviation is given in the $90 \%$ reliability interval. $E_{\mathrm{a}}(\mathrm{b})$ and $E_{\mathrm{a}}(\mathrm{gb})$ are independent of the grain size. For the Zircar samples there is a tendency that $E_{\mathrm{a}}(\mathrm{gb})$ decreases with increasing grain size. The weighted mean values of $E_{\mathrm{a}}(\mathrm{b})$ and $E_{\mathrm{a}}(\mathrm{gb})$ are $(103.4 \pm 0.6)$ and $(110.0 \pm 1.3) \mathrm{kJ} \mathrm{mole}^{-1}$ respectively for the alkoxide samples with $x=0.164$ and $(95.3 \pm 0.6)$ and $(102.5 \pm 1.0) \mathrm{kJ} \mathrm{mole}^{-1}$ respectively for the Zircar samples. The activation energy of the grain boundary is about $7 \mathrm{~kJ}$ mole $\mathrm{e}^{-1}$ higher than that of the bulk and this is in good agreement with literature values $[5,6,9-12]$ for fluorite-type solutions in this concentration region. The activation energy of 
the bulk and the grain boundary conductivity increases with increasing lanthanide (Y) content.

The bulk conductivity is independent of the grain size, as shown in table 2 . The grain boundary conductivity increases with increasing grain size, as shown in figs. 7 and 8 . The grain boundary conductivity at 723 $\mathrm{K}$ as a function of the grain size is given in fig. $9 *$.

For small grain sizes $\sigma_{\mathrm{gb}}$ increases linearly with $d_{\mathrm{g}}$ while for large grains $\sigma_{\mathrm{gb}}$ is independent of $d_{\mathrm{g}}$. The grain size where the material changes from one regime to the other appears to be dependent on the impurity level or the Yttrium concentration, see fig. 9. The behaviour of small grain sizes is well described by relation (1), assuming that $\sigma_{\mathrm{gb}}^{\mathrm{sp}}$ and $\delta_{\mathrm{gb}}$ are constant. From the relation between $C_{\mathrm{gb}}$ and $d_{\mathrm{g}}$ it can be concluded that $\delta_{\mathrm{gb}}$ is constant, as will be shown below. Therefore, we can conclude that for small grain sizes $\sigma_{\mathrm{gb}}^{\mathrm{sp}}$ is constant, i.e. independent of $d_{\mathrm{g}}$. This means that the total conductivity is determined only

* In this figure the data for samples sintered at $1973 \mathrm{~K}$ are not shown, because the cooling procedure was quite different. The absolute value of $\sigma_{\mathrm{gb}}$ is strongly influenced by the cooling procedure as will be shown below and is also reported by Bernard [5]. The grain boundary conductivity of the alkoxide and Zircar sample sintered at $1973 \mathrm{~K}$ is $38.9 \times 10^{-2}$ and $9.6 \times 10^{-2} \Omega^{-1} \mathrm{~m}^{-1}$ respectively.

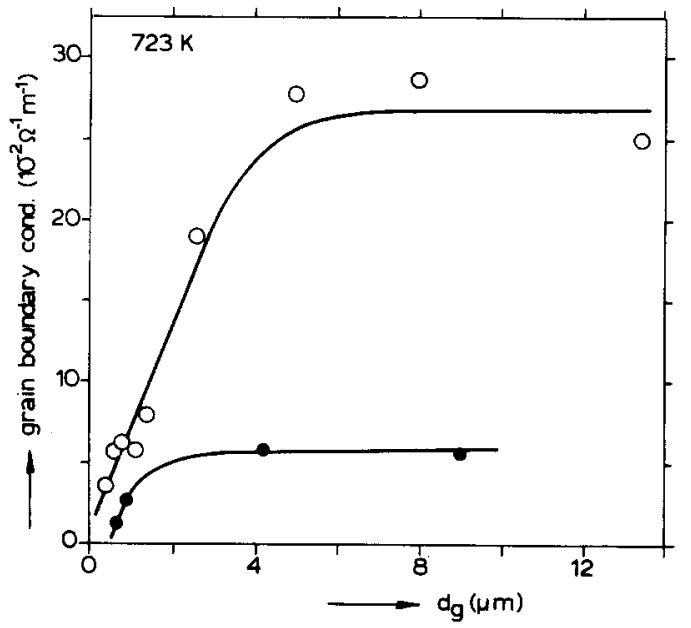

Fig. 9. Grain boundary conductivity at $723 \mathrm{~K}$ as a function of the grain size. $\circ$ : alkoxide samples $(x=0.164), \bullet$ : Zircar samples. by the number of grain boundaries. For large grain sizes $\sigma_{\mathrm{gb}}$ is independent of $d_{\mathrm{g}}$. Because $\delta_{\mathrm{gb}}$ is constant we can conclude from relation (1) that for large grain sizes $\sigma_{\mathrm{gb}}^{\mathrm{sp}}$ decreases with increasing $d_{\mathrm{g}}$.

The grain boundary conductivity of the less pure Zircar samples is lower than that for the alkoxide samples, as shown in fig. 9. From the work of Bernard [5] we can conclude that this difference is much too large to be ascribed to the higher porosity of the Zircar samples. A porosity of $10 \%$ results in a decrease of the conductivity of about $20 \%$. Therefore, this difference must be ascirbed to the higher impurity level or the lower lanthanide content of the Zircar samples. From table 1 and using the $\sigma_{\mathrm{gb}}$ value of the alkoxide sample with 11.9 at \% Y we can conclude that this difference must be ascribed to the $\mathrm{Ca}$ and $\mathrm{Ti}$ impurities.

The grain boundary conductivity is strongly influenced by the cooling procedure. A sample with a grain size of $0.36 \mu \mathrm{m}$ (sintered at $1456 \mathrm{~K}$ ) was "quenched" from $1436 \mathrm{~K}$ by removing the sample suddenly from a furnace and cooling by natural convection. The bulk and the grain boundary conductivity at $723 \mathrm{~K}$ for the samples subjected to the cooling procedure described in section 2.1 was $2.55 X$ $10^{-2}$ and $3.40 \times 10^{-2} \Omega^{-1} \mathrm{~m}^{-1}$ respectively, and for the "quenched" sample $2.55 \times 10^{-2}$ and $8.42 \times$ $10^{-2} \Omega^{-1} \mathrm{~m}^{-1}$, respectively. This indicates a de-

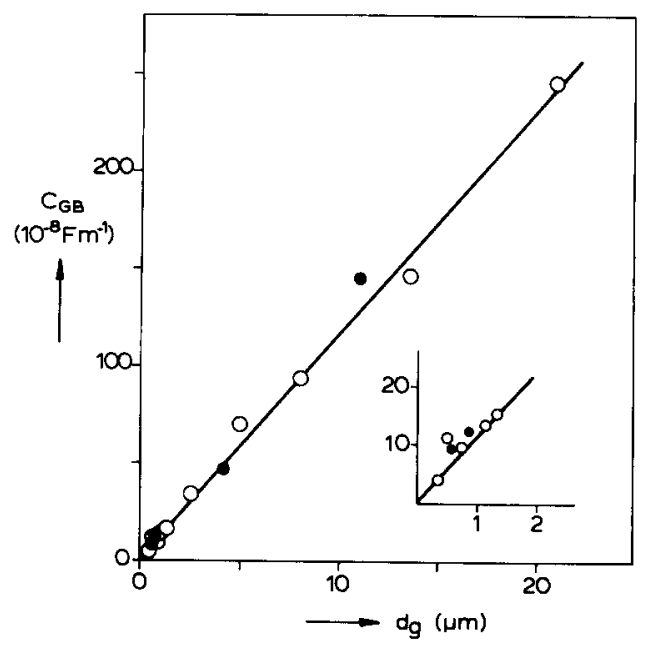

Fig. 10. Grain boundary capacity as a function of the grain size. o: alkoxide samples $(x=0.164), \bullet$ : Zircar samples. 
crease in the grain boundary conductivity for annealed or slowly cooled samples.

The grain boundary capacity is independent of temperature and increases linearly with increasing grain size, as shown in fig. 10. Using relation (2) we can conclude that the thickness of the grain boundary is independent of the grain size. As a reasonable value for $\epsilon_{r}(\mathrm{gb})$ the bulk value was taken, $\epsilon_{r}=70$ [6, $11,28]$. From (2) we calculate $\delta_{\mathrm{gb}}=5.4 \mathrm{~nm}$.

\section{Discussion}

\subsection{Evaluation of models}

\subsubsection{Brick layer model}

Our samples are characterized by low impurity levels (table 1), well-developed microstructures (fig. 3) and a well-defined grain size distribution (fig. 4). The small depression of the grain boundary semicircle indicates a small scatter of relaxation times [24,25] and can be correlated with homogeneous grain boundaries $\ddagger$. The most suitable model to describe our ceramic materials is the brick layer model proposed by Van Dijk and Burggraaf [6]. It is assumed that the ceramic samples consist of grains with a high conductivity, separated by relatively thin, uniform grain boundaries. The grain boundary consists of a homogeneous layer and there is no parallel conduction path along the grain boundaries. As shown in section 3 this model described our results well and the results of other investigators are in good agreement. From Inozemtsev's [8] and Joffe's [9] data we found a linear relation between $C_{\mathrm{gb}}$ and $d_{\mathrm{g}}$. With relation (2), assuming $\epsilon_{r}(\mathrm{gb})=70$, we calculated from their $C_{\mathrm{gb}}$ data for $\delta_{\mathrm{gb}}$ a value of $9.0 \mathrm{~nm}$. From Joffe's [9] and Bernard's [5] data we found a linear relation between $\sigma_{\mathrm{gb}}$ and $d_{\mathrm{g}}$ at $723 \mathrm{~K}$ over a large range of grain sizes, although some measuring-points deviate (see introduction). These deviations can possibly be ascribed to the influence of cooling procedures. How-

\footnotetext{
₹ Wet chemically prepared (homogeneous) powders show small depression angles [this work, 5,6,9] whereas materials made by solid-state reaction show large depression angles $[2,8,10,12]$. A large depression angle is also observed for sodium beta aluminas [24]. This material shows conduc tion anisotropy and a large scatter of relaxation times can be expected.
}

ever, these authors did not find that $\sigma_{\mathrm{gb}}$ becomes constant at large grain sizes as reported in this study. Inozemtsev [8] found for samples sintered in the regions $2100-2500 \mathrm{~K} \mathrm{a} \sigma_{\mathrm{gb}}-d_{\mathrm{g}}$ relation having about the same form as found in this study. The brick layer model will be further discussed in section 4.2. At present attention will be paid to other models proposed in literature.

\subsubsection{Bauerle model}

Bauerle [1] developed a model for ceramics containing inhomogeneously-distributed second phases. This second phase shows no ionic conductivity and constriction of the current appears at the grain boundary. This model results in a electrical circuit with a series connection of the bulk and grain boundary resistance, as shown in fig. 5a. However, SEM showed no second phases in the alkoxide and Zircar samples. The impurity levels of these samples are low. Therefore, the presence of second phases is not very probable and if present it would be located on multiple grain junctions $[23,26]$ and no strong constriction can be expected. Therefore, this model is not appropriate for describing our results.

\subsubsection{Parallel model}

Schouler et al. $[11,27]$ proposed a parallel model, which is also used by Bernard [5]. In this model the grain boundary is partially covered by a segregated phase. At places where this phase is absent, the ions can pass without any hindrance and this group of charge carriers is associated with a resistance $R(1)$. On the other hand, when a segregated phase is present on the grain boundaries, the oxygen ions are "blocked". The microscopic interpretation of this effect is not very clear. This groups of charge carriers should be associated with a resistance $R(2)$ and a capacity $C(2)$. The equivalent electrical circuit for the electrolyte consists of $R(1)$ and parallel with it a series combination of $R(2)$ and $C(2)$. The proposed circuit is electrically equivalent to the electrolyte part shown in fig. 5a and results in the same frequency dispersion diagram as shown in fig. $5 \mathrm{~b}$. The relavant data are determined using the following equations:

$R(1)=R_{2}(A / L)$,

$R(2)=\left[R_{2} R_{1} /\left(R_{2}-R_{1}\right)\right](A / L)$, 
$C(2)=\left[\left(R_{2}-R_{1}\right) / R_{2} R_{1} \omega_{2}\right](L / A)$.

An inhomogeneous segregation is very plausible with a badly-developed microstructure and/or higher impurity levels. Although this is not the case with our materials, we analysed our data in terms of the parallel model. The activation energy of $R(1)$ and $R(2)$ is independent of the grain size and has a value of $(105.0 \pm 0.6)$ and $(102.0 \pm 0.6) \mathrm{kJ} \mathrm{mole}^{-1}$ for the alkoxide samples and $(96.8 \pm 0.5)$ and $(93.8 \pm 0.6) \mathrm{kJ}$ mole ${ }^{-1}$ for the Zircar samples respectively. Table 3 gives $R(2)$ at $723 \mathrm{~K}$ as a function of the grain size. For small grain sizes $R(2)$ increases with increasing grain size and is constant for large grain sizes. $C(2)$ depends on temperature and is independent of the grain size (table 3). Bernard [5] introduces a new parameter $\alpha$, representing the fraction of charge carriers blocked at the boundary:

$\alpha=\left(R_{2}-R_{1}\right) / R_{2}$.

As shown in table 3, $\alpha$ decreases with increasing grain size and becomes constant at large grain sizes.

Table 3

Electrical data belonging to the parallel model proposed by Schouler $[11,21]$

\begin{tabular}{llll}
\hline$d_{\mathrm{g}}$ & $\begin{array}{l}R(2), 723 \mathrm{~K} \\
(\Omega \mathrm{m})\end{array}$ & $\begin{array}{l}C(2), 723 \mathrm{~K} \\
\left(10^{-8} \mathrm{Fm}^{-1}\right)\end{array}$ & $\begin{array}{l}\alpha \\
(\%)\end{array}$ \\
\hline
\end{tabular}

alkoxide material, $x=0.164$

\begin{tabular}{lcccc}
\hline 0.36 & 91.5 & 1.29 & 42.9 \\
0.55 & 77.3 & 2.57 & 37.4 \\
0.75 & 78.0 & 2.13 & 37.2 \\
1.11 & 76.5 & 3.19 & 36.6 \\
1.35 & 94.3 & 2.13 & 30.8 \\
2.54 & 126 & 1.44 & 18.4 \\
5.0 & 258 & 0.98 & 11.2 \\
9.2 & 261 & 1.26 & 10.9 \\
13.5 & 248 & 2.37 & 11.9 \\
21.4 a) & 368 & 1.71 & 8.0 \\
Zircar material, $x=0.140$ & & \\
\hline & & & \\
0.65 & 44.0 & 19.7 & 72.1 \\
0.86 & 39.9 & 12.4 & 62.4 \\
4.2 & 59.3 & 14.8 & 42.9 \\
11 & 58.4 & 42.8 & 41.5 \\
55 a) & 118 & 43.3 & 25.6 \\
\hline
\end{tabular}

a) These samples were subjected to a different temperature treatment (see text).
As shown above, our data can be described phenomenologically by means of the elements $R(1), R(2)$ and $C(2)$ from the parallel model. However, the interpretation on the basis of this equivalent circuit is incompatible with our results and literature data. According to Schouler [11,27] and Bernard [5] $R(2)$ should decrease with increasing temperature due to partial (re)solution of the segregated phase, resulting in a decrease of $\alpha$ and $C(2)$. From the parallel model it follows that the decrease of $\alpha$ and $C(2)$ as a function of temperature are correlated. Fig. 11 shows that Schouler's correlation applies for example for an alkoxide sample, where both $\alpha$ and $C(2)$ decrease slightly as a function of temperature. However, for a Zircar sample $\alpha$ decreases only slightly in the temperature region $600-800 \mathrm{~K}$, whereas $C(2)$ decreases by more than a factor two. Moreover, solution of the segregated phase at temperatures of $800-1000 \mathrm{~K}$ is not very probable and is contrary to the results of Bernard's [5] quenching experiments, showing that solution or formation of the segregated phase occurs at temperatures of $1570-2100 \mathrm{~K}$. Finally, as a consequence of the parallel model, $E_{\mathrm{a}}(R(1))$ has to be equal to $E_{\mathrm{a}}(\mathrm{b})$. This is found experimentally for $\left(\mathrm{ZrO}_{2}\right)_{1-x}\left(\mathrm{YO}_{1.5}\right)_{x}(x=0.12-0.18)$ [this work, 5, $11]$, but is not found for $\left(\mathrm{MO}_{2}\right)_{1-x}\left(\mathrm{YO}_{1.5}\right)_{x}(\mathrm{M}=$

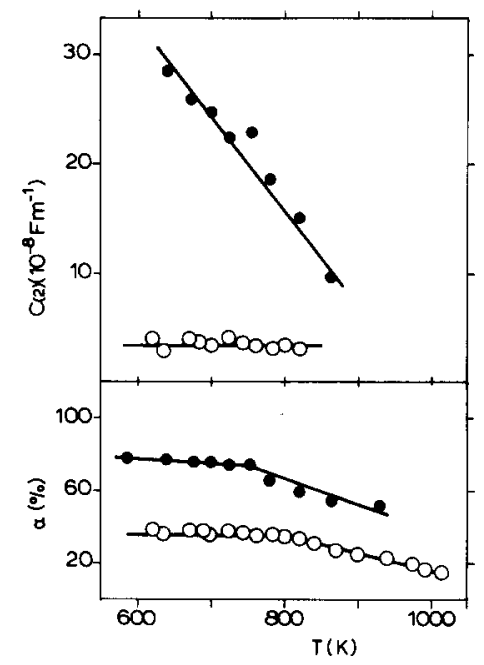

Fig. 11. Capacity $C(2)$ and blocking factor $\alpha$, belonging to the parallel model, as a function of temperature. $\bullet$ : Zircar sample, $d_{\mathrm{g}}=0.65 \mu \mathrm{m}, \mathrm{o}:$ alkoxide sample, $d_{\mathrm{g}}=1.11 \mu \mathrm{m}$. 
Ce, Th; $x=0.00-0.02)[11,13]$ and according to our analysis for $\left(\mathrm{ZrO}_{2}\right)_{1-x}\left(\mathrm{GdO}_{1.5}\right)_{x}$ with $x=0.495-$ 0.532 (pyrochlore [6], made by the alkoxide synthesis). For these reasons we reject the parallel model for the above-mentioned systems.

From the ceramic characteristics of our samples together with the experimental data we conclude that the brick layer model developed by Van Dijk and Burggraaf [6] is the most suitable one to describe the homogeneous, pure or slightly doped materials with a well-developed ceramic microstructure which are used in our studies. Some features will be further discussed in section 4.2 .

\subsection{The nature of the grain boundary layer}

In section 3.2. it was shown that the brick layer model gives a good description of our experimental results. The nature of the grain boundary layer in this model was not specified and will be discussed in this section. The grain boundary effect is clearly demonstrated by comparing $\sigma_{\mathrm{gb}}^{\mathrm{sp}}$ and $\sigma_{\mathrm{b}}$. From relation (1) using $\delta_{\mathrm{gb}}=5.4 \mathrm{~nm}$ we calculated for $\sigma_{\mathrm{gb}}^{\mathrm{sp}}$ at $723 \mathrm{~K}$ $3.65 \times 10^{-4} \Omega^{-1} \mathrm{~m}^{-1}$ for the alkoxide samples with $d_{\mathrm{g}}<4 \mu \mathrm{m}$, whereas $\sigma_{\mathrm{b}}=3.45 \times 10^{-2} \Omega^{-1} \mathrm{~m}^{-1}$. The conductivity of the grain boundary is about 100 times lower than that of the bulk. Using $\delta_{\mathrm{gb}}=9.0 \mathrm{~nm}$ we calculated for Ioffe's [9] samples $(4.5-18 \mu \mathrm{m}) \sigma_{\mathrm{gb}}^{\mathrm{sp}}=$ $1.26 \times 10^{-4} \Omega^{-1} \mathrm{~m}^{-1}$, whereas $\sigma_{\mathrm{b}}=3.40 \times 10^{-2}$ $\Omega^{-1} \mathrm{~m}^{-1}$.

The nature of the grain boundary may be determined by micro cracks, mismatch of the lattices, segregation, space charge or a combination of these effects. The grain boundary conductivity is strongly influenced by the purity, cooling procedure [this work, 5,14$]$ and substituent concentration $[6,11,13]$. Hence, it is not very probable that the grain boundary effect is mainly determined by micro cracks and mismatch, which are not assumed to be strongly dependent on the variations of the parameters used in our experiments. Therefore, the grain boundary effect must be ascribed to space charges and or segregation. This will be discussed now.

Grain boundaries in an ionic solid may have an electronic potential $V$, which may be in the order of a few tenths of a Volt [22]. The influence of s space charge can be estimated. A positive space charge is assumed. Due to this the concentration of vacancies with the same sign decreases strongly. For the ratio between the bulk and grain boundary conductivity the following relation can be deduced from [29]:

$\sigma_{\mathrm{b}} / \sigma_{\mathrm{gb}}^{\mathrm{sp}}=\left(2 \psi_{0}\right)^{-1 / 2} \int_{0}^{\delta} \mathrm{gb}^{/ 2} \mathrm{e}^{\psi} \mathrm{d} x$

and

$\psi=2 q V / k T$,

with $2 q$ is the charge of the vacancy and $\psi_{0}$ the potential at $x=0$, i.e. the potential at the grain boundary. At $900 \mathrm{~K}$ (above the bend) the observed value of $\sigma_{\mathrm{b}} / \sigma_{\mathrm{gb}}^{\mathrm{sp}}$ is 56 . Using eqs. (13) and (14) a surface potential of $0.20 \mathrm{~V}$ is obtained. It follows from the calculation that the difference between $E_{\mathrm{a}}(\mathrm{b})$ and $E_{\mathrm{a}}(\mathrm{gb})$ should be $33 \mathrm{~kJ}$ mole $\mathrm{e}^{-1}$, the experimentally measured difference being $30 \mathrm{~kJ}$ mole ${ }^{-1}$. However, from the calculations it follows that only $3 \%$ of the vacancies is mobile. At $723 \mathrm{~K}$ (below the bend) the observed value of $\sigma_{\mathrm{b}} / \sigma_{\mathrm{gb}}^{\mathrm{sp}}$ is 94 . A surface potential of $0.23 \mathrm{~V}$ is obtained. The difference between $E_{\mathrm{a}}(\mathrm{b})$ and $E_{\mathrm{a}}(\mathrm{gb})$ should be $38 \mathrm{~kJ}$ mole $\mathrm{e}^{-1}$, whereas experimentally a value of $7 \mathrm{~kJ} \mathrm{~mole}^{-1}$ is found. It was calculated that in this case also $3 \%$ of the vacancies is mobile. However, in this calculation the effects of associate formation was ignored. If this effect is taken into account a better agreement between experimental and calculated results may be obtained. Although many features are not clear at this moment, we can conclude that space charges may account (at least partly) for the observed grain boundary phenomena. Further calculations taking into account ordering and associate formation are now performed.

In ceramic materials grain boundary segregation of solute components or impurities is well known [22, $23,26]$. Segregation of one or more components in the grain boundary can be attributed to various driving forces which have the common feature of causing a resulting decrease in the total free energy of the system. These driving forces are: compensation of space charges by aliovalent ions, reduction of strain energy and lowering of the surface tension. In the first place, assuming an enrichment of the grain boundary with yttrium ions of 16.4 at $\%$ to 21 at $\%$ the higher activation energy of the grain boundary can be explained. This enrichment, however, lowers the conductivity of the grain boundary layer only by a factor of about two [12]. To explain the large difference 
between $\sigma_{\mathrm{b}}$ and $\sigma_{\mathrm{gb}}^{\mathrm{sp}}$ a decreased mobility of the vacancies or a decreased concentration of vacancies by trapping has to be assumed. Finally, low concentration of impurities may contribute to these effects. Low concentrations of $\mathrm{Si}^{4+}, \mathrm{Al}^{3+}, \mathrm{Fe}^{3+}$ and $\mathrm{Bi}^{3+}$ impurities in yttria stabilized zirconia increase $E_{\mathrm{a}}(\mathrm{gb})$ and decrease $\sigma_{\mathrm{gb}}[11,14]$. In the concentration region, in which these impurities are present, the effect on the conductivity is not sufficiently large to explain the observed phenomena unless large grain boundary segregation factors will be found. For $\mathrm{Al}_{2} \mathrm{O}_{3}$ and $\mathrm{Fe}_{2} \mathrm{O}_{3}(0.1-2.0$ mole $\%)$ is was concluded [14] that segregation factors of 2 or 3 are present and consequently simple segregation of these impurities cannot sufficiently explain the observed phenomena. Surface analysis of the grain boundary is necessary to determine enrichment of yttrium ions and/or impurities. Preliminary Auger experiments on a fractured surface showed a considerable enrichment of yttrium on the grain boundary surface [30]. More experiments are being performed.

\section{Conclusions}

(1) The grain boundary phenomena are succesfully interpreted in terms of the brick layer model. In this model the grain boundary consists of a relatively thin, homogeneous layer with a low conductivity compared to the bulk.

(2) From the relation between the capacity and the grain size we concluded that the grain boundary thickness is independent of the grain size and has a value of about $5.4 \mathrm{~nm}$.

(3) The activation energy of the grain boundary is $7 \mathrm{~kJ}$ mole ${ }^{-1}$ higher than that of the bulk.

(4) The specific conductivity of the grain boundary is for small grains $(<2-4 \mu \mathrm{m})$ independent of the grain size and is 100 times lower than that of the bulk. For large grains $(>2-4 \mu \mathrm{m})$ the specific conductivity of the grain boundary decreases with increasing grain size.

(5) The grain boundary conductivity is decreased by a factor $5(T=723 \mathrm{~K})$ by an increase in the impurity content from about $10 \times 10^{-2} \mathrm{wt} \%$ to $50 \times$ $50^{-2} \mathrm{wt} \%$. Slow cooling or annealing of rapidly quenched samples decreases the grain boundary conductivity.
(6) Space charges and/or segregation of main components or impurities in the grain boundary layer can only explain the results if trapping of vacancies is assumed.

\section{Acknowledgement}

Ing. M.A.C.G. van de Graaf is thanked for his help concerning the preparation of the alkoxide powder and Mr. H. Kruidhof for the chemical analysis. The authors are much indebted to Dr. L. Heijne for the stimulating discussions concerning space charge phenomena. The financial assistance from Philips N.V. (Elcoma) is acknowledged.

\section{References}

[1] J.E. Bauerle, J. Phys. Chem. Solids 30 (1969) 2657.

[2] M.V. Inozemtsev and M.V. Perfil'ev, Elektrokhimiya 11 (1975) 1031.

[3] N.M. Beekmans and L. Heijne, Electrochim. Acta 21 (1976) 303.

[4] K.C. Radford and R.J. Bratton, J. Mater. Sci. 14 (1979) 66.

[5] H. Bernard, Ph.D. Thesis, Grenoble (1980).

[6] T. van Dijk and A.J. Burggraaf, Phys. Status Solidi (A) 63 (1981) 229.

[7] K.El. Adham and A. Hammou, Preprints 9th Intern. Symp. Reactivity of Solids (Cracow, 1980) p. 82.

[8] M.V. Inozemtsev, M.V. Perfil'ev and A.S. Lipilin, Elektrokhimiya 10 (1974) 1471.

[9] A.I. Ioffe, M.V. Inozemtsev, A.S. Lipilin, M.V. Perfil'ev and S.V. Karpachov, Phys. Status Solidi (A) 30 (1975) 87.

[10] S.H. Chu and M.A. Seitz, J. Solid State Chem. 23 (1978) 297.

[11] E. Schouler, Ph.D. Thesis, Grenoble (1979).

[12] M.V. Inozemtsev and M.V. Perfil'ev, Elektrokhimiya 12 (1976) 1236.

[13] Da Yu Wang and A.S. Nowick, J. Solid State Chem. 35 (1980) 325.

[14] M.J. Verkerk, A.J.A. Winnubst and A.J. Burggraaf, to be published.

[15] K.S. Mazdiyasni, C.T. Lynch and J.S. Smith Il, J. Am. Ceram. Soc. 50 (1967) 532.

[16] M.A.C.G. van de Graaf, K. Keizer and A.J. Burggraaf, Science of Ceramics 10, ed. H. Hausner (DKG, Weiden, 1980) p. 83.

[17] H. Kruidhof, Anal. Chimica Acta 99 (1978) 193.

[18] Dutch Normalization Institute, NEN 3130, Aug. 1968.

[19] H.J. Oel, Ber. Dtsch. Keram. Ges. 43 (1966) 624. 
[20] M.I. Mendelsohn, J. Am. Ceram. Soc. 52 (1969) 443.

[21] R.E.W. Casselton, Phys. Status Solidi (A) 2 (1979) 571.

[22] W.D. Kingery, J. Am. Ceram. Soc. 57 (1974) 1.

[23] W.D. Kingery, J. Am. Ceram. Soc. 57 (1974) 74.

[24] L.C. de Jonghe, J. Mater. Sci. 14 (1979) 33.

[25] H.J. de Bruin and A.D. Franklin, J. Electroanal. Chem. 118 (1981) 405.
[26] P.F. Bongers and P.E.C. Franken, Advan. Ceram. 1 (1981) 38 .

[27] E. Schouler, G. Giroud and M. Kleitz, J. Chem. Phys. 70 (1973) 1309.

[28] W.N. Lawless, Phys. Rev, B22 (1980) 3122.

[29] S.K. Tiku and F.A. Kröger, J. Am. Ceram. Soc. 63 (1980) 183.

[30] A.J.A. Winnubst and A.J. Burggraaf, private communication. 